\title{
Multidimensional Connection Cloud Model Coupled with Improved CRITIC Method for Evaluation of Eutrophic Water
}

\author{
Daguo Wu $\mathbb{D}^{\mathrm{D}},{ }^{1}$ Jiahui Yan $\mathbb{D}^{2},{ }^{2}$ Mingwu Wang $\mathbb{D}^{2},{ }^{2}$ Guangyao Chen $\mathbb{D}^{2},{ }^{2}$ Juliang Jin, ${ }^{2}$ \\ and Fengqiang Shen ${ }^{2}$ \\ ${ }^{1}$ Anhui \& Huaihe River Institute of Hydraulic Research, Hefei 230088, China \\ ${ }^{2}$ School of Civil and Hydraulic Engineering, Hefei University of Technology, Hefei 230009, China \\ Correspondence should be addressed to Mingwu Wang; wanglab307@foxmail.com
}

Received 24 October 2021; Accepted 23 December 2021; Published 11 January 2022

Academic Editor: Krishna Murari Pandey

Copyright (c) 2022 Daguo Wu et al. This is an open access article distributed under the Creative Commons Attribution License, which permits unrestricted use, distribution, and reproduction in any medium, provided the original work is properly cited.

\begin{abstract}
The degree of eutrophication in the water environment is deepening. For the appropriate treatment of eutrophication, it is essential to evaluate it accurately. However, the evaluation of eutrophication has not been well solved because it is full of uncertainty. Herein, a multidimensional connection cloud model, combined with the improved CRITIC (Criteria Importance Through Inter-criteria Correlation) method, was put forward here to assess water eutrophication and depict the randomness, ambiguity, and interaction of evaluation factors. First, an improved CRITIC was adopted to determine indicator weight so that the correlation among different indicators and more information were depicted. Secondly, a multidimensional connection cloud was simulated to characterize fuzzy indicators and ambiguous classification boundary values according to classification criteria. Next, the connection degree was calculated relative to the evaluation standard. The eutrophication grade was specified under the "maximum connection degree" principle. At last, the effectiveness and practicality of the model proposed here were affirmed by two cases and comparisons with supplementary methods. The results suggest that the proposed model can avoid shortcomings of the original CRITIC method and cloud model, and make the assessment result more realistic.
\end{abstract}

\section{Introduction}

Eutrophication is becoming more severe because many untreated wastewaters enter the water directly in nature [1]. As we know, eutrophication induces algae to multiply [2], so it will harm the entire water environment [3]. The hazards comprise the following aspects [4]. First, the atmosphere and water are cut off because of algae on the water surface. The respiration of aquatic organisms consumes a large amount of dissolved oxygen, making the water lack oxygen and producing red tide or blooms. Second, eutrophication causes many deaths of aquatic animals and plants, which may endanger the entire water environment. It also makes the water corrupt and reduces the transparency of water. Third, the corpses of aquatic animals and plants can pollute water sources, expand the scope of water pollution, and increase the difficulty and cost of treatment. Fourth, eutrophication promotes the growth of algae. Algae may secrete toxins, which harm aquatic organisms and cause chronic poisoning of the human body through marine products. The Organization for Economic Cooperation and Development (OECD) suggested that the lower limit of the total phosphorus density of eutrophic water should be $0.035 \mathrm{mg} / \mathrm{L}$. According to this standard, the eutrophication of water in some parts of the world is severe [5]. The International Eutrophication Research Cooperation Program has been conducted to investigate global eutrophication. And it is found that $30 \%-40 \%$ of lakes and reservoirs in the world are suffering from eutrophication [6-9]. Unluckily, there are likewise numerous reports on ocean eutrophication $[10,11]$. In general, eutrophication has had a significant impact on the global environment. It is of far-reaching significance to appraise water quality accurately.

Numerous researchers have importance to eutrophication evaluation methods $[12,13]$. Tu et al. [14] utilized the single factor pollution index method to assess the pollution status of the coastal water at Beitangkou in Tianjin. However, eutrophication was affected by numerous factors due to 
the intricacy of the water environment [15]. The single factor evaluation method with a few indicators could not fully reflect the level of water eutrophication [16]. Some scholars have proposed the comprehensive trophic level index (TLI) for eutrophication evaluation [17]. The TLI method combined the simpleness with the accuracy of complete multivariate judgment. However, various factors of eutrophication were non-deterministic, non-linear, and vague. The distribution of nutrients in the water was uneven while the number of sampling points was limited [18]. The TLI method was unsuitable for lakes and reservoirs in all regions [19].

The water environment was full of randomness, ambiguity, and uncertainty. Conventional evaluation methods like TLI cannot reflect the detailed characteristics of eutrophication. Therefore, Lin et al. [20] applied the principle of set pair analysis to assess the degree of lake eutrophication. Set pair analysis has been widely used to study the system with certainty and uncertainty [21]. However, its comments on identity, discrepancy, and contrary were brief. And there were still shortcomings in the analysis of uncertain systems. The eutrophication mechanism was very complicated because it was produced under the combined action of physical, chemical, and biological processes. To comprehensively consider the randomness and ambiguity $[22,23]$, the normal cloud model [24] has been utilized to assess the classification of eutrophication. The conversion from qualitative research to quantitative study was realized in the normal cloud model. Drops, simulated by the normal cloud, might not conform to the actual distribution characteristics in a limited range $[25,26]$ since the indicator is distributed normally in an undefined interval. The actual distribution of indicators in the asymmetric intervals might be ignored.

In some cases, the above shortcomings might result in inaccurate conversion trends at the classification threshold [25]. So one-dimensional connection cloud model was put forward by Wang and Jin [27] to reflect the transformation of uncertainty. However, there might be a tedious calculation process when employing a one-dimensional cloud model for processing questions with multiple factors and many statistical samples. Fortunately, there was a multidimensional cloud model [26]. Yao et al. [28] proposed a multidimensional similarity cloud model for considering data error and improving the adaptability to multiple problems. The impact of certainty and uncertainty within different indicators was felt in the model.

Nevertheless, it needed massive data to assign numerical characteristics, which caused inconvenience for the application in several samples. Thus, the following two opinions are significant for developing the evaluation model: (1) the evaluation model should align with the actual distribution of samples; (2) it should improve the ambiguity and randomness of the indicator.

As we know, assigning weights to indicators is of great significance [29]. There are different importance and internal information in various indicators [30]. Current weighting methods can be divided into subjective and objective methods. Methods for determining subjective weight, like the analytic hierarchy process [31], the Delphi method [32], and the expert-evaluation-based method [33], need to give some initial messages based on the knowledge or experience of the decision-maker [34]. Because experts have rich experience in this field, the subjective weighting method effectively reflects the importance of different standards. It leads to reasonable judgments based on the actual situation. However, many psychological studies prove that the observed behavior of human beings does not conform to the expected utility curve. Human judgments are usually of individual preferences [35] due to outdated ideas of decision-makers or preference for a specific standard [36]. In addition, decision-makers may not fully recognize the issues under consideration. And the initial information provided by them may be finite [37]. Subjective weight inevitably involves personal preferences. When various standards are concerned, the provided information may be pretty complicated. There are some differences between the subjective and objective weighting methods. In the latter, the decisionmaker is not required to offer preliminary information, and the weight is decided under actual data [38]. Thereby they can effectively avoid the deviation of subjective methods. Some objective criteria weighting methods are based on different theories, such as the entropy method [39, 40], the deviation maximization method, the criterion impact loss method, and the integrated determination method [41]. The entropy method and CRITIC [42] are the most frequent objective weighting. The entropy method with a simple calculation procedure does not consider the relationship between various indicators, limiting its application scope [43]. The CRITIC method assigns the weight in the light of the contrast intensity characterizing each separate factor and the conflict between two factors [44]. It can consider the trend of a single indicator and analyze the correlation among different indicators [45]. However, the CRITIC method still has two defects. First, the standard deviation is a measure of contrast intensity. The standard deviation of a group of indicator values is calculated as a check against the degree of difference in indicator values. And the unit and magnitude of an index value are often different from those of another index value. So, it is not always applicable to use the standard deviation to measure the degree of variation; second, the calculation formula for the conflict between two indicators involves the correlation coefficient.

The larger the correlation coefficient value, the stronger the positive correlation between two indicators. The less the conflict, the greater the repetitiveness of the information contained in two indicators, the smaller the weight number. But the correlation coefficient between the index $i$ and index $j$ may be a negative number. The correlation reflected by the positive correlation coefficient is different from that reflected by the negative correlation coefficient with the same absolute value. It is unreasonable to directly use the correlation coefficient to measure the collision between indicators. Consequently, the improved CRITIC method is discussed here to deal with the above shortcomings.

In this article, a new multidimensional connection cloud model combined with an improved CRITIC was provided for water eutrophication evaluation. Numerical 
characteristics are obtained through the "identity-discrepancy-contrary" of set pair analysis, which simultaneously characterizes the certainty and uncertainty relationship among different indicators and standards. Furthermore, an improved CRITIC is taken to identify the weight of indicators. The certainty and uncertainty among some indicators and classifications are unified in the proposed model. The transformation situation of adjacent grades can also be considered in the method. Two cases containing 54 sets of samples and comparisons with supplementary methods were executed to prove the rationality of the proposed method.

\section{Methodology}

2.1. Improved CRITIC Method. The CRITIC method, proposed by Diakoulaki [45], shows the contrast intensity and conflict of evaluation indicators. The CRITIC method efficiently solves multicriteria decision problems that contain much information. It is an uncomplicated calculation process where the views of decision-makers are covered, and the interaction among the given standards can be characterized.

The weight reflects the amount of information incorporated in each attribute. The contrast intensity of indicators is closely related to the attributes as one of the sources of information. Besides determining the power of contrast by the standard deviation, CRITIC reveals the conflict in multistandard decision making. The correlation coefficient is generally utilized to denote the magnitude and direction of the competition. The independence coefficient $\eta_{j}$ measures the disagreement between an indicator and other indicators.

$$
\eta_{j}=\sum_{i=1}^{n}\left(1-r_{i j}\right)
$$

where $r_{i j}$ denotes the correlation coefficient of evaluation indicators $i$ and $j$ [45].

However, the standard deviation cannot directly compare the contrast intensity because measurement units and magnitude of different indicators are often various. In addition, there are positive or negative correlations between multiple indicators. And the correlations of indicators reflected by positive and negative correlations with the same absolute value should be the same. It is unreasonable to measure conflict by the independence coefficient $\eta_{j}$. To overcome the above shortcomings, "the variation coefficient" is introduced here to replace standard deviation, which measures the contrast strength of indicators. And the calculation formula of the independence coefficient for measuring conflicts is given as,

$$
\eta_{j}=\sum_{i=1}^{n}\left(1-\left|r_{i j}\right|\right) .
$$

For the improved CRITIC method, the detailed determination procedures of the variation coefficient and the independence coefficient are as follows:
(1) Construct the original evaluation matrix $\mathbf{X}=\left(x_{i j}\right)_{m \times n}$, where $x_{i j}(i=1,2, \ldots, m ; j=1,2, \ldots, n)$ is the data of the $j$-th indicator of the $i$-th sample.

(2) The standardization process for the original data matrix. The Z-score method is utilized to deal with the matrix $\mathbf{X}^{*}$.

$$
\begin{aligned}
& x_{i j}^{*}=\frac{x_{i j}-\bar{x}_{j}}{s_{j}}, \\
& \bar{x}_{j}=\frac{1}{m} \sum_{i=1}^{m} x_{i j}, \\
& s_{j}=\sqrt{\frac{1}{m-1} \sum_{i=1}^{m}\left(x_{i j}-\bar{x}_{j}\right)^{2}},
\end{aligned}
$$

where $\bar{x}_{j}$ is the average of all sample data of indicator $j ; s_{j}$ is the standard deviation; $\mathbf{X}^{*}=\left(x_{i j}^{*}\right)_{m \times n}$ denotes the standardized matrix.

(3) Calculate the variation coefficient of each evaluation index.

$$
v_{j}=\frac{s_{j}}{\bar{x}_{j}},
$$

where $v_{j}$ is the variation coefficient of indicator $j$.

(4) Determine the correlation coefficient matrix $\mathbf{R}=$ $\left(r_{k l}\right)_{n \times n}$ according to the standardized matrix $\mathbf{X}^{*}$.

$$
r_{k l}=\frac{\sum_{i=1}^{m}\left(x_{i k}^{*}-\bar{x}_{k}^{*}\right)\left(x_{i l}^{*}-\bar{x}_{l}^{*}\right)}{\sqrt{\sum_{i=1}^{m}\left(x_{i k}^{*}-\bar{x}_{k}^{*}\right)^{2}} \sqrt{\sum_{i=1}^{m}\left(x_{i l}^{*}-\bar{x}_{l}^{*}\right)^{2}}},
$$

where $r_{k l}$ denotes the correlation coefficient between index $k$ and index $l ; x_{i k}^{*}$ and $x_{i l}^{*}$ are the standardized measured values of index $k$ and index $l$ of sample $i$ in $\mathrm{X}^{*}$, respectively; $\bar{x}_{k}^{*}$ and $\bar{x}_{l}^{*}$ respectively denote the average of standardized values of measured values of index $k$ and index $l$ in $\mathbf{X}^{*}$.

(5) Calculate the independence coefficient of each indicator. The independence coefficient is used to assess the degree of correlation among different indicators. And the independence coefficient of each indicator is determined according to equation (2).

2.2. Connection Cloud Model. The cloud model was created to link qualitative notion with quantitative uncertainty and incarnate the ambiguity and randomness of objective things [46]. Denote $\boldsymbol{Q}$ by a qualitative concept in the quantitative domain $\boldsymbol{P}$ with a definite value in a finite interval. If the numerical value $x(x \in \boldsymbol{P})$ is a stochastic actualization of $\boldsymbol{Q}$, there will be a random number $\mu(x)$ belonging to $x$ in $\boldsymbol{Q} . \mu(x)$ is called the certainty degree. It measures the certainty-uncertainty relationship between $x$ and the concept $\boldsymbol{Q}$. The distribution condition of $x$ within the universe " $P$ " is called "cloud". $X$ is named as one of the cloud drops [47]. The certainty $\mu(x)$ of the cloud drop $x$ is given by: 


$$
\mu(x)=\exp \left(-\frac{(x-E x)^{2}}{2\left(E n^{\prime}\right)^{2}}\right),
$$

where Ex represents the mathematical expectation; En' obeys normal distribution $N\left(E n, H e^{2}\right)$; $E n$ and $H e$ are entropy and hyper entropy, respectively. En is used to determine the acceptable numerical range of qualitative concepts under discussion. $\mathrm{He}$ is a measure of uncertainty [48].

Generally, the index values are required to be normally distributed in the normal cloud model. In actual engineering, the distribution condition of index values may not meet this requirement. Moreover, it does not consider the finite interval of the index value distribution and the conversion relationship between the final judged grade and the two adjacent grades. Luckily, the original distribution features of evaluation indexes are available in the connection cloud model. Because it uniformly and dialectically describes the definite and uncertain relationship of information, the relationship between indicators and each grade, and the characteristics of the transition between adjacent grades [27]. The calculation model of the connection degree of the connection cloud drop is given as

$$
\mu(x)=\exp \left(-\frac{9}{2}\left|\frac{x-E x}{3 E n^{\prime}}\right|^{k}\right),
$$

where $x \sim N\left(E x, E n^{\prime 2}\right), E n^{\prime} \sim N\left(E n, H e^{2}\right) ; k$ is called as the order of the connection cloud. In the connection cloud, the cloud of grade $i$ of indicator $j$ is composed of asymmetric connection clouds on the left and right sides with the dividing point $E x_{i}$. Let the total number of cloud drops be $M$. $\left(E x_{i}, E n_{i}, H e_{i}, k_{i}\right)$, and $M$ is the numerical characteristics of connection cloud drops. The corresponding calculation formulas are given by

$$
\begin{aligned}
\mu\left\{x^{i}\left(x 1^{i}, x 2^{i}, \cdots x m^{i}\right)\right\} & =\exp \left(-\frac{9}{2} \sum_{j=1}^{m}\left|\frac{x j^{i}-E x_{j}^{i}}{3 E n_{j}^{i}}\right|^{k_{j}^{i}}\right), \\
E x_{j}^{i} & =\frac{C_{\min j}^{i}+C_{\max j}^{i}}{2}, \\
H e_{j}^{i} & =\beta, \\
E n_{j}^{i} & =\frac{a_{j}^{i}}{3},
\end{aligned}
$$

where $E x_{j}^{i}, E n_{j}^{i}, H e_{j}^{i}, C_{\max j}^{i}, C_{\min j}^{i}$ and $\beta(=0.01$ here) are the mathematical expectation of grade $i$ of indicator $j$, entropy, hyper entropy, the upper and floor limits of the range for grade $i$ of indicator $j$, and the atomization coefficient, respectively. To uniformly and quantitatively describe the transformation situation of evaluation results in different grades, a connection degree is used to specify the tendency of the index value belonging to each grade. Connection degree at the boundary that belongs to the two adjacent grades is defined as the same. For example, the lower limit of the grade $i-1$ may belong to $i-1$ or not belong to $i-1$. In other words, the "discrepancy" relationship may be converted to the "identity" or "contrary" relationship. Based on the principle of set pair analysis, it will belong to the "identity" if the connection degree is within $[0.5,1]$; it will belong to the "discrepancy" if the connection degree is within $\left[e^{-4.5}, 0.5\right]$; it will belong to the "contrary" if the connection degree is within $\left[0, \mathrm{e}^{-4.5}\right]$. Then the order $k_{j}^{i}$ of the semi-interval of the connection cloud at grade $i$ of indicator $j$ is given as

$$
k_{j}^{i}=\frac{\ln (\ln 4 / 9)}{\ln \left|x_{j}^{i}-E x_{j}^{i} / 3 E n_{j}^{i}\right|},
$$

where $x_{j}^{i}$ is $C_{\max j}^{i}$ or $C_{\min j}^{i}$.

2.3. Model Formulation. The eutrophication evaluation process based on the improved CRITIC and multidimensional connection cloud model is shown in Figure 1.

Detailed steps [49] are depicted as follows.

Step 1. Determine the index and the number of indicators for the eutrophication classification. In addition, establish the grading standards. Let the number of grades be $n$. So, the evaluation range of each index corresponding to the grade is identified. Then judge whether the evaluation index is monotonously increasing or decreasing at the level of $1 \sim n$. The mechanism of water eutrophication, with many influencing factors, is complex. Chemical factors (such as nitrogen, phosphorus, iron, calcium, carbon dioxide, organic matter, etc.), physical factors (such as light and temperature) and biomass factors are included. In 2001, China National Environmental Monitoring Centre proposed to take total phosphorus (TP), total nitrogen (TN), chlorophyll-a (Chl-a), permanganate index $\left(\mathrm{COD}_{\mathrm{Mn}}\right)$ and transparency $(\mathrm{SD})$ as the main influencing factors. Carson et al. [50] integrated some indicators to evaluate nutritional status, including transparency (SD), chlorophyll-a (Chl-a), total phosphorus (TP) and so on. Physical and chemical indicators (water temperature, dissolved oxygen, $\mathrm{pH}$, conductivity, turbidity, transparency, chlorophyll-a, algae density, permanganate index and nutrient indicators (ammonia nitrogen, total phosphorus, total nitrogen)) and other indicators are generally included in the routine monitoring process for water quality [51]. While evaluating specific water samples, not all of the above indicators are involved in the evaluation. Only some of them are chosen.

Step 2. Calculate the digital characteristics $\left(E x, E n_{\mathrm{L}}, E n_{\mathrm{R}}\right.$, $\left.H e, k_{\mathrm{L}}, k_{\mathrm{R}}\right)$ for the $m$-dimensional connection cloud and determine the number $M$ of cloud drops. A kind of $m$ dimensional cloud for some grades is simulated. In the onedimensional connection cloud model belonging to index $j$, there are apparent differences between middle-grade clouds $(i=2,3, \ldots, n-1)$ and end-grade clouds ( $i=1$ and $n$ ). The half of the clouds at both ends, far away from middle-grade clouds, actually obey a uniform distribution of which the connection degree is 1 . The generating process of cloud drops is listed as follows. (a) Produce normal random figures $E n^{\prime}\left(E n_{1}^{\prime}, E n_{2}^{\prime}, \ldots, E n_{m}^{\prime}\right)$ based on mathematical expectation $E n\left(E n_{1}, E n_{2}, \ldots, E n_{m}\right)$ and the 


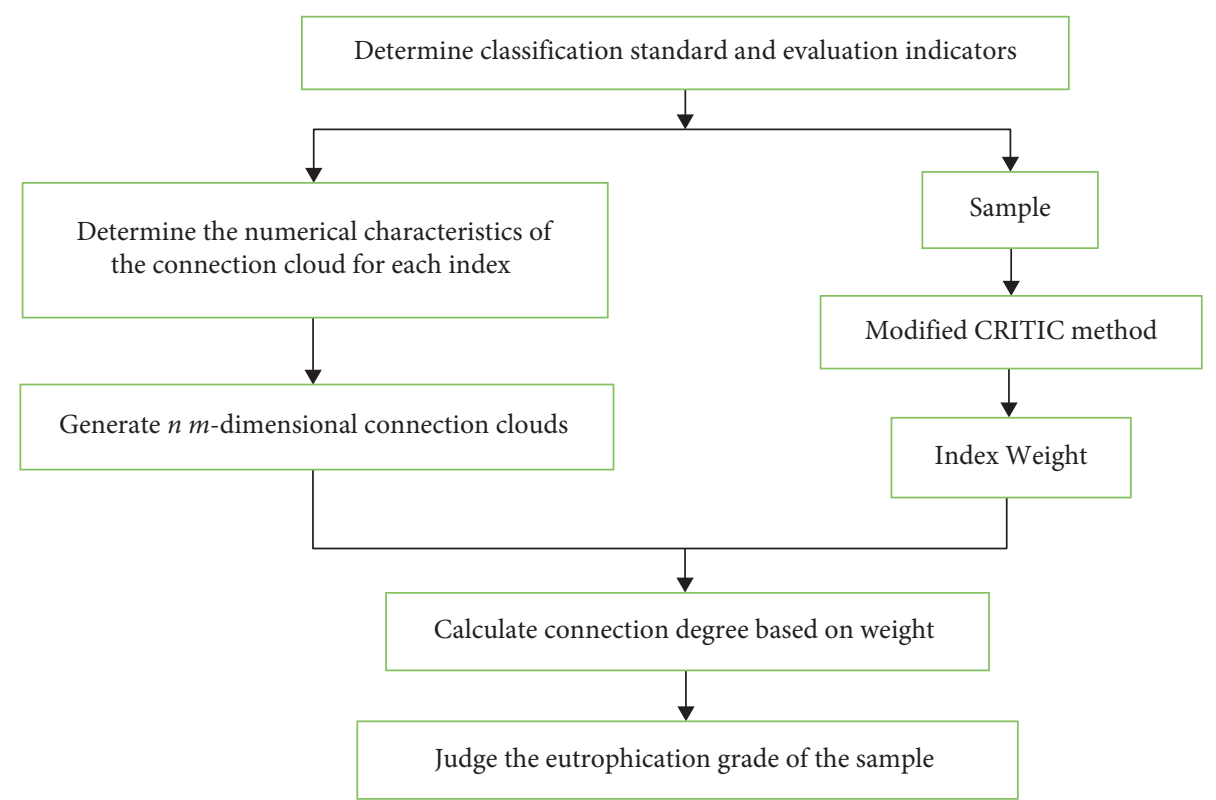

FIGURE 1: Evaluation process of eutrophication carried out by multidimensional connection cloud model coupled with improved CRITIC.

standard deviation $\mathrm{He}\left(\mathrm{He}_{1}, \mathrm{He}_{2}, \ldots, \mathrm{He}_{m}\right)$. (b) Generate normal random numbers $x\left(x_{1}, x_{2}, \ldots, x_{m}\right)$ according to the mathematical expectation $E x\left(E x_{1}, E x_{2}, \ldots, E x_{m}\right)$ and the standard deviation $E n^{\prime}\left(E n_{1}^{\prime}, E n_{2}^{\prime}, \ldots, E n_{m}^{\prime}\right)$. (c) Calculate the connection degree of cloud drop according to formula (10). (d) Repeat steps a $\sim \mathrm{c}$ to produce $M$ cloud drops ( $X\left\{x_{1}\right.$, $\left.\left.x_{2}, \ldots, x_{m}\right\}, \mu\left(x\left(x_{1}, x_{2}, \ldots, x_{m}\right)\right)\right)$.

Step 3. Specify the weight $w_{j}$ of the indicator $j$. To objectively reflect indicator information, the improved CRITIC is utilized for assigning the indicator weight. According to "the variation coefficient" and the independence coefficient, the quantitative coefficient that characterizes the comprehensive information and the degree of independence of each evaluation index is given by

$$
C_{j}=v_{j} \eta_{j}
$$

where $C_{j}$ reveals the amount of information that is contained in indicator $j$. Then the weight of indicator $j$ is given as

$$
w_{j}=\frac{C_{j}}{\sum_{j=1}^{n} C_{j}} .
$$

Step 4. The aggregation of the connection degree of the sample relative to the classification standard.

$$
\mu\left\{x^{i}\left(x 1^{i}, x 2^{i}, \cdots x m^{i}\right)\right\}=\exp \left(-\frac{9}{2} \sum_{j=1}^{m} w_{j}\left|\frac{x j^{i}-E x_{j}^{i}}{3 E n_{j}^{i^{i}}}\right|^{k_{j}^{i}}\right) .
$$

Step 5. Specify the grade depending on the maximum connection degree.

\section{Case Study}

3.1. Case One. From the literature [52], data is collected from 24 lakes and reservoirs. Chlorophyll-a (Chl-a), total phosphorus (TP), total nitrogen (TN), permanganate index $\left(\mathrm{COD}_{\mathrm{Mn}}\right)$, and transparency (SD) were chosen as indicators. The eutrophication degree was divided into six grades. The classification standard is given in Table 1. And the data for samples are listed in Table 2.

Standardize sample data under the Z-score method. Then apply formulas $(4) \sim(6)$ to acquire the mean, variance and "variation coefficient" as follows. $\overline{\mathbf{x}}=[74.9663,254.9583$, $3463.9167,8.4046,0.7221], \boldsymbol{s}=[94.0515,253.9431,4148.0761$, $5.8058,0.7849]$ and $v=[1.2546,0.9960,1.1975,0.6908$, 1.0870]. According to formula (7), the correlation coefficient matrix is given as

$$
R=\left[\begin{array}{rrrrrr}
1.0000 & 0.8722 & 0.7607 & 0.8379 & -0.4736 \\
0.8722 & 1.0000 & 0.6773 & 0.7447 & -0.4367 \\
0.7607 & 0.6773 & 1.0000 & 0.6462 & -0.4230 \\
0.8379 & 0.7447 & 0.6462 & 1.0000 & -0.5270 \\
-0.4736 & -0.4367 & -0.4230 & -0.5270 & 1.0000
\end{array}\right] .
$$

Index weight $w_{j}=(0.1751,0.1672,0.2364,0.1137$, 0.3076 ) can be obtained according to equations (2), (15), and (16). Take eutrophication grade I as an example here. According to formulas (11)-(14), the characteristic values $\left(E x, E n_{\mathrm{L}}, E n_{\mathrm{R}}, \mathrm{He}, k_{\mathrm{L}}\right.$, and $\left.k_{\mathrm{R}}\right)$ corresponding to each indicator have been calculated as listed in Table 3 .

A two-dimensional connection cloud for chlorophyll a (Chl-a) and permanganate index $\left(\mathrm{COD}_{\mathrm{Mn}}\right)$ was constructed to make readers comprehend the concept introduced in this article intuitively. It was shown in Figure 2. For comparison, the permanganate index 
TABLe 1: Classification standard of water eutrophication [52].

\begin{tabular}{|c|c|c|c|c|c|}
\hline Classification & Chl-a $\left(\mathrm{mg} / \mathrm{m}^{3}\right)$ & $\mathrm{TP}\left(\mathrm{mg} / \mathrm{m}^{3}\right)$ & $\mathrm{TN}\left(\mathrm{mg} / \mathrm{m}^{3}\right)$ & $\mathrm{COD}_{\mathrm{Mn}}(\mathrm{mg} / \mathrm{L})$ & $\mathrm{SD}(\mathrm{m})$ \\
\hline I & $\leq 1.0$ & $\leq 2.5$ & $\leq 30$ & $\leq 0.3$ & $\geq 10.0$ \\
\hline II & $\leq 2.0$ & $\leq 5.0$ & $\leq 50$ & $\leq 0.4$ & $\geq 5.0$ \\
\hline III & $\leq 4.0$ & $\leq 25$ & $\leq 300$ & $\leq 2.0$ & $\geq 1.5$ \\
\hline IV & $\leq 10$ & $\leq 50$ & $\leq 500$ & $\leq 4.0$ & $\geq 1.0$ \\
\hline $\mathrm{V}$ & $\leq 64$ & $\leq 200$ & $\leq 2000$ & $\leq 10$ & $\geq 0.4$ \\
\hline VI & $>64$ & $>200$ & $>2000$ & $>10$ & $<0.4$ \\
\hline
\end{tabular}

TABLe 2: Sample data for case one [52].

\begin{tabular}{|c|c|c|c|c|c|}
\hline Samples & Chl-a $\left(\mathrm{mg} / \mathrm{m}^{3}\right)$ & $\mathrm{TP}\left(\mathrm{mg} / \mathrm{m}^{3}\right)$ & $\mathrm{TN}\left(\mathrm{mg} / \mathrm{m}^{3}\right)$ & $\mathrm{COD}_{\mathrm{Mn}}(\mathrm{mg} / \mathrm{L})$ & $\mathrm{SD}(\mathrm{m})$ \\
\hline 1 & 1.86 & 22 & 246 & 3.09 & 2.77 \\
\hline 2 & 1.49 & 46 & 358 & 1.49 & 1.72 \\
\hline 3 & 3.52 & 23 & 932 & 5.96 & 1.46 \\
\hline 4 & 3.00 & 29 & 1086 & 2.87 & 0.67 \\
\hline 5 & 10.79 & 25 & 1220 & 4.11 & 1.42 \\
\hline 6 & 4.99 & 52 & 2374 & 2.75 & 0.28 \\
\hline 7 & 3.77 & 194 & 3201 & 6.96 & 0.44 \\
\hline 8 & 14.47 & 77 & 1000 & 3.74 & 0.36 \\
\hline 9 & 7.24 & 153 & 1671 & 16.25 & 0.48 \\
\hline 10 & 11.80 & 115 & 1786 & 4.01 & 0.28 \\
\hline 11 & 44.43 & 108 & 1309 & 7.11 & 0.49 \\
\hline 12 & 298.86 & 931 & 15273 & 16.58 & 0.23 \\
\hline 13 & 58.95 & 161 & 2478 & 6.94 & 0.43 \\
\hline 14 & 75.69 & 141 & 1417 & 7.23 & 0.38 \\
\hline 15 & 54.77 & 287 & 2206 & 10.38 & 0.53 \\
\hline 16 & 119.51 & 372 & 3038 & 9.92 & 0.34 \\
\hline 17 & 149.45 & 428 & 5350 & 13.40 & 0.22 \\
\hline 18 & 153.59 & 232 & 15692 & 13.51 & 0.22 \\
\hline 19 & 162.92 & 743 & 7337 & 14.46 & 0.31 \\
\hline 20 & 323.51 & 643 & 6777 & 25.26 & 0.15 \\
\hline 21 & 168.14 & 663 & 4073 & 10.08 & 0.22 \\
\hline 22 & 4.96 & 316 & 1270 & 5.96 & 0.73 \\
\hline 23 & 120.60 & 228 & 2630 & 8.22 & 0.22 \\
\hline 24 & 0.88 & 130 & 410 & 1.43 & 2.98 \\
\hline
\end{tabular}

TABLE 3: Numerical characteristic values of multidimensional connection cloud at grade I.

\begin{tabular}{|c|c|c|c|c|c|}
\hline Parameter & Chl-a $\left(\mathrm{mg} / \mathrm{m}^{3}\right)$ & $\mathrm{TP}\left(\mathrm{mg} / \mathrm{m}^{3}\right)$ & $\mathrm{TN}\left(\mathrm{mg} / \mathrm{m}^{3}\right)$ & $\mathrm{COD}_{\mathrm{Mn}}(\mathrm{mg} / \mathrm{L})$ & $\mathrm{SD}(\mathrm{m})$ \\
\hline$E x$ & 0.50 & 1.25 & 15.00 & 0.15 & 10.50 \\
\hline$E n_{L}$ & 0.6667 & 1.6667 & 16.6667 & 0.1333 & 1.8333 \\
\hline$E n_{R}$ & 0.8333 & 7.0833 & 86.6667 & 0.5500 & 1.1667 \\
\hline $\mathrm{He}$ & 0.01 & 0.01 & 0.01 & 0.01 & 0.01 \\
\hline$k_{L}$ & 1.3519 & 1.3433 & 1.5540 & 1.7984 & 0.7790 \\
\hline$k_{R}$ & 1.6790 & 1.7046 & 2.2061 & 3.1115 & 0.6055 \\
\hline
\end{tabular}

$\left(\mathrm{COD}_{\mathrm{Mn}}\right)$ was used to construct a one-dimensional connection cloud. It was shown in Figure 3.

The connection degree of multidimensional connection cloud was calculated by formula (17). Based on the maximum connection degree, the eutrophication grade was specified. In addition, comparisons with evaluation upshots of the one-dimensional connection cloud model combined with the game theory [53], the comprehensive connection cloud model based on the analytic hierarchy process [53], the improved fuzzy comprehensive evaluation approach [52], the projection pursuit model [52] and the multidimensional connection cloud model [53] were also conducted. Their results are illustrated in Table 4.
It can be known from Table 4 that, except for samples 2, 6,12 , and 15 , all grades judged by the model proposed in this paper do in agreement with those judged by other approaches. In the paper model, $u($ III $)=0.5170$ and $u($ IV $)=$ 0.4855 for sample 2 indicate that the eutrophication grade of sample 2 is most likely to belong to grade III and then to grade IV. However, one of the evaluation indicator values of sample 2 is in grade II (Chl-a), two are in grade III $\left(\mathrm{COD}_{\mathrm{Mn}}\right.$ and SD), and the remaining two are in grade IV (TP and $\mathrm{TN})$. The value of.

TN is closer to the boundary of grade III. Therefore, it is more rational to judge sample 2 as grade III. $u(\mathrm{~V})=0.9603$ and $u(I V)=0.7805$ for sample 6 indicate that its 


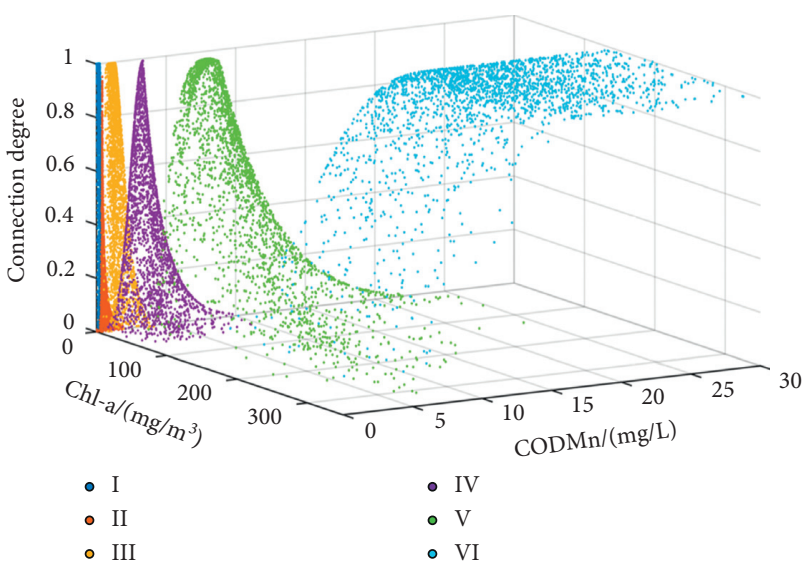

FIgURe 2: Two-dimensional connection cloud model for Chl-a and $\mathrm{COD}_{\mathrm{Mn}}$.

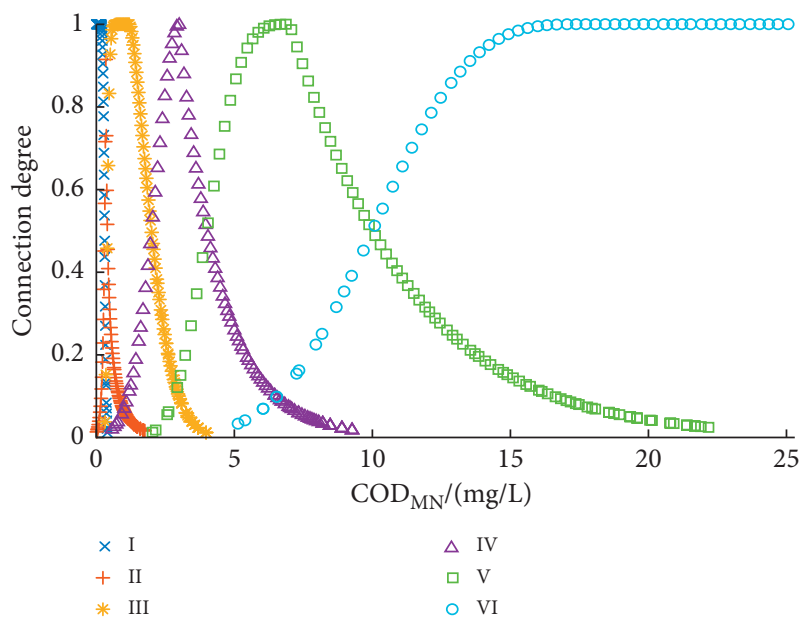

FIGURE 3: One-dimensional connection cloud model for $\mathrm{COD}_{\mathrm{Mn}}$.

eutrophication grade is the most likely to belong to grade $\mathrm{V}$ and then to grade IV. For the 5 evaluation index data of sample 6, two of them (Chl-a and $\left.\mathrm{COD}_{\mathrm{Mn}}\right)$ are at grade IV, one (TP) is at grade V, and two (TN, SD) are at grade VI. It is more reasonable to specify the eutrophication grade of sample 6 as V than IV. Four indicator values of sample 12 are in grade VI. Only one indicator value of that is in grade $\mathrm{V}$. Obviously, it is reasonable that the eutrophication grade of sample 12 is judged as VI. There is $u(\mathrm{~V})=0.5404$ and $u(\mathrm{VI})=0.4291$ in sample 15 . It indicates that sample 15 is most likely to belong to grade $\mathrm{V}$ and there is a tendency for sample 15 to transform to grade VI. As for sample 15, the actual data of Chl-a and SD are at grade V while the data of TP, TN and $\mathrm{COD}_{\mathrm{Mn}}$ are at grade VI. However, the weight of Chl-a and SD is higher because the weight order is $\mathrm{SD}>\mathrm{TN}>\mathrm{Chl}-\mathrm{a}>\mathrm{TP}>\mathrm{COD}_{\mathrm{Mn}}$. And measured values of $\mathrm{TP}, \mathrm{TN}$ and $\mathrm{COD}_{\mathrm{Mn}}$ are closer to the boundary value of grade $\mathrm{V}$. Therefore, it is reasonable that the eutrophication grade of sample 15 is assigned to grade $\mathrm{V}$.

Take sample 2 as an example. There are a total of 7 evaluation methods. Among them, 4 ways give an evaluation result of grade III. And the evaluation result of method B also grades III. After simple statistics for all samples, it is found that the evaluation grade given by method $B$ is the same as the grade with the most occurrences. So, B is the most credible. Based on the result of method B, the similarity rate $S_{k}$ is calculated as follows:

$$
S_{k}=\frac{p_{s}}{p}
$$

$S_{k}$ is used to characterize how similar the evaluation result of the $k$-th method is to that of the B method. $p_{s}$ is the number of samples with the same evaluation grade as the $B$ method. $p$ represents the overall number of samples $(p=24$ in case one, $p=30$ in case two). Based on method B, the similarity rate of the model proposed in the article has reached $95.8 \%$.

The similarity rates of methods other than the proposed model in Table 4 are listed as follows: $70.8 \%$ of the multidimensional connection cloud model based on the traditional CRITIC method; $95.8 \%$ of comprehensive connection cloud model where the analytic hierarchy process [53] is utilized to decide the weight of various indicators; $83.3 \%$ of improved fuzzy evaluation method; $95.8 \%$ of cast shadow model; $87.5 \%$ of multidimensional connection cloud model.

3.2. Case Two. As we know, the evaluation indicator system significantly influences the result. The causes of eutrophication in different water environments are varied. Thirty water samples in the literature [54] were selected to conduct a case study as a supplement. Herein, various evaluation indicators were considered. Furthermore, comparisons with the results obtained from the one-dimensional connection cloud model, the empirical value method [54], the multidimensional connection cloud model, and the multidimensional connection cloud model based on traditional CRITIC were supplemented to affirm the superiority and advancement of the proposed model. Statistics of the sample are presented in Table 5.

In case two, total phosphorus (TP), chemical oxygen demand (COD), transparency (SD) and total nitrogen (TN) were selected as indicators for eutrophication evaluation. There were five grades in total. The grading standards are shown in Table 6 . The calculation processes of index weight, digital characteristics, and connection degree were similar to those in Example 1. The correlation coefficient and weight of each indicator were all determined through the improved CRITIC. They are shown in Table 7 and Table 8. And the final calculation results and comparative analysis are listed in Table 9.

It was observed from Table 9 that, except for samples 27, 29 , and 30 , conclusions obtained by the proposed method are virtually identical to those of other ways. Further discussions about different analytical methods are also carried out to analyze the proposed effectiveness and practicality. For sample 27, water eutrophication grade is appraised as grade IV with empirical value, but grade $\mathrm{V}$ with other methods. Through individual inspection of each indicator, it is found that three indicators of this sample are at grade $\mathrm{V}$ and one index is at grade IV. And the value of the index TP 
TABLE 4: Evaluation results and comparisons.

\begin{tabular}{|c|c|c|c|c|c|c|c|c|c|c|c|c|c|}
\hline \multirow[t]{2}{*}{ Samples } & \multicolumn{6}{|c|}{$\mu(x)$} & \multirow[b]{2}{*}{ Proposed model } & \multirow[b]{2}{*}{$\mathrm{A}$} & \multirow[b]{2}{*}{ B [53] } & \multirow[b]{2}{*}{ C [53] } & \multirow[b]{2}{*}{$\mathrm{D}[52]$} & \multirow[b]{2}{*}{$\mathrm{E}[52]$} & \multirow[b]{2}{*}{$\mathrm{F}[53]$} \\
\hline & I & II & III & IV & $\mathrm{V}$ & VI & & & & & & & \\
\hline 1 & 0.0000 & 0.0412 & 0.5599 & 0.1156 & 0 & 0.0001 & III & III & III & III & III & III & III \\
\hline 2 & 0.0000 & 0.0168 & 0.2381 & 0.1695 & 0.0054 & 0.0017 & III & IV & III & IV & III & III & IV \\
\hline 3 & 0.0000 & 0.0029 & 0.0008 & 0.2772 & 0.0450 & 0.0057 & IV & $\mathrm{V}$ & IV & IV & IV & IV & IV \\
\hline 4 & 0.0000 & 0.0023 & 0.0000 & 0.1728 & 0.1539 & 0.0209 & IV & $\mathrm{V}$ & IV & IV & IV & IV & IV \\
\hline 5 & 0.0000 & 0.0001 & 0.0000 & 0.3058 & 0.1302 & 0.0070 & IV & $\mathrm{V}$ & IV & IV & IV & IV & IV \\
\hline 6 & 0.0000 & 0.0001 & 0.0000 & 0.0347 & 0.1496 & 0.0885 & $\mathrm{~V}$ & VI & $\mathrm{V}$ & $\mathrm{V}$ & IV & $\mathrm{V}$ & IV \\
\hline 7 & 0.0000 & 0.0000 & 0.0000 & 0.0160 & 0.2468 & 0.1990 & $\mathrm{~V}$ & VI & $\mathrm{V}$ & $\mathrm{V}$ & $\mathrm{V}$ & $\mathrm{V}$ & $\mathrm{V}$ \\
\hline 8 & 0.0000 & 0.0000 & 0.0000 & 0.0630 & 0.6267 & 0.0797 & $\mathrm{~V}$ & $\mathrm{~V}$ & $\mathrm{~V}$ & $\mathrm{~V}$ & $\mathrm{~V}$ & $\mathrm{~V}$ & $\mathrm{~V}$ \\
\hline 9 & 0.0000 & 0.0000 & 0.0000 & 0.0272 & 0.4490 & 0.1836 & V & $\mathrm{V}$ & $\mathrm{V}$ & V & V & V & $\mathrm{V}$ \\
\hline 10 & 0.0000 & 0.0000 & 0.0000 & 0.0332 & 0.4269 & 0.1575 & $\mathrm{~V}$ & $\mathrm{~V}$ & $\mathrm{~V}$ & $\mathrm{~V}$ & $\mathrm{~V}$ & $\mathrm{~V}$ & $\mathrm{~V}$ \\
\hline 11 & 0.0000 & 0.0000 & 0.0000 & 0.0378 & 0.8534 & 0.1904 & $\mathrm{~V}$ & $\mathrm{~V}$ & $\mathrm{~V}$ & $\mathrm{~V}$ & $\mathrm{~V}$ & $\mathrm{~V}$ & $\mathrm{~V}$ \\
\hline 12 & 0.0000 & 0.0000 & 0.0000 & 0.0000 & 0.0237 & 0.9999 & VI & VI & VI & VI & VI & VI & VI \\
\hline 13 & 0.0000 & 0.0000 & 0.0000 & 0.0151 & 0.5776 & 0.3923 & $\mathrm{~V}$ & VI & $\mathrm{V}$ & $\mathrm{V}$ & $\mathrm{V}$ & $\mathrm{V}$ & $\mathrm{V}$ \\
\hline 14 & 0.0000 & 0.0000 & 0.0000 & 0.0194 & 0.5919 & 0.3391 & $\mathrm{~V}$ & $\mathrm{~V}$ & $\mathrm{~V}$ & $\mathrm{~V}$ & $\mathrm{~V}$ & $\mathrm{~V}$ & $\mathrm{~V}$ \\
\hline 15 & 0.0000 & 0.0000 & 0.0000 & 0.0121 & 0.5404 & 0.4291 & $\mathrm{~V}$ & VI & VI & VI & $\mathrm{V}$ & VI & $\mathrm{V}$ \\
\hline 16 & 0.0000 & 0.0000 & 0.0000 & 0.0022 & 0.2710 & 0.7914 & VI & VI & VI & VI & VI & VI & VI \\
\hline 17 & 0.0000 & 0.0000 & 0.0000 & 0.0004 & 0.0744 & 0.9871 & VI & VI & VI & VI & VI & VI & VI \\
\hline 18 & 0.0000 & 0.0000 & 0.0000 & 0.0001 & 0.0691 & 0.9219 & VI & VI & VI & VI & VI & VI & VI \\
\hline 19 & 0.0000 & 0.0000 & 0.0000 & 0.0001 & 0.0939 & 0.9417 & VI & VI & VI & VI & VI & VI & VI \\
\hline 20 & 0.0000 & 0.0000 & 0.0000 & 0.0000 & 0.0235 & 1.0000 & VI & VI & VI & VI & VI & VI & VI \\
\hline 21 & 0.0000 & 0.0000 & 0.0000 & 0.0005 & 0.0967 & 0.9216 & VI & VI & VI & VI & VI & VI & VI \\
\hline 22 & 0.0000 & 0.0000 & 0.0000 & 0.0659 & 0.4249 & 0.0811 & $\mathrm{~V}$ & $\mathrm{~V}$ & $\mathrm{~V}$ & $\mathrm{~V}$ & $\mathrm{~V}$ & $\mathrm{~V}$ & $\mathrm{~V}$ \\
\hline 23 & 0.0000 & 0.0000 & 0.0000 & 0.0036 & 0.1407 & 0.7392 & VI & VI & VI & VI & VI & VI & VI \\
\hline 24 & 0.0000 & 0.0062 & 0.0025 & 0.0412 & 0.0000 & 0.0001 & IV & IV & IV & IV & IV & IV & IV \\
\hline
\end{tabular}

Note: A represents the multidimensional connection cloud model based on traditional CRITIC method; B represents the one-dimensional connection cloud model combined with game theory; $\mathrm{C}$ represents the comprehensive connection cloud model while the analytic hierarchy process calculates the weight; $\mathrm{D}$ denotes the improved fuzzy evaluation method; E represents the projection and pursuit model; F represents the multidimensional connection cloud model.

TABLE 5: Sample data for case two [54].

\begin{tabular}{|c|c|c|c|c|}
\hline Samples & TP (ug/L) & $\mathrm{COD}(\mathrm{mg} / \mathrm{L})$ & $\mathrm{SD}(\mathrm{m})$ & $\mathrm{TN}(\mathrm{mg} / \mathrm{L})$ \\
\hline 1 & 0.658 & 0.059 & 50.857 & 0.001 \\
\hline 2 & 0.559 & 0.051 & 42.650 & 0.015 \\
\hline 3 & 0.106 & 0.034 & 67.902 & 0.009 \\
\hline 4 & 0.978 & 0.061 & 42.207 & 0.010 \\
\hline 5 & 0.646 & 0.051 & 47.659 & 0.015 \\
\hline 6 & 1.233 & 0.259 & 36.899 & 0.040 \\
\hline 7 & 3.225 & 0.349 & 24.079 & 0.047 \\
\hline 8 & 2.821 & 0.133 & 23.709 & 0.042 \\
\hline 9 & 1.426 & 0.176 & 16.260 & 0.020 \\
\hline 10 & 1.947 & 0.098 & 19.699 & 0.035 \\
\hline 11 & 15.338 & 0.918 & 3.359 & 0.185 \\
\hline 12 & 22.127 & 1.779 & 4.942 & 0.240 \\
\hline 13 & 20.269 & 1.681 & 2.606 & 0.281 \\
\hline 14 & 9.171 & 1.479 & 3.252 & 0.145 \\
\hline 15 & 16.739 & 1.308 & 8.979 & 0.290 \\
\hline 16 & 24.736 & 2.621 & 1.530 & 1.182 \\
\hline 17 & 91.674 & 3.710 & 2.106 & 0.627 \\
\hline 18 & 105.427 & 6.403 & 1.176 & 0.661 \\
\hline 19 & 106.776 & 5.898 & 0.993 & 1.145 \\
\hline 20 & 93.002 & 5.341 & 1.038 & 0.606 \\
\hline 21 & 627.669 & 20.039 & 0.409 & 2.627 \\
\hline 22 & 297.816 & 13.171 & 0.191 & 3.050 \\
\hline 23 & 370.796 & 21.733 & 0.460 & 3.068 \\
\hline 24 & 279.420 & 17.600 & 0.347 & 3.850 \\
\hline 25 & 281.502 & 22.646 & 0.317 & 1.464 \\
\hline 26 & 130.000 & 10.300 & 0.350 & 2.760 \\
\hline 27 & 105.000 & 10.700 & 0.400 & 2.000 \\
\hline 28 & 20.000 & 1.400 & 4.500 & 0.220 \\
\hline 29 & 30.000 & 6.260 & 0.250 & 1.670 \\
\hline 30 & 20.000 & 10.130 & 0.500 & 0.230 \\
\hline
\end{tabular}


TABLE 6: Classification standard of water eutrophication evaluation index [54].

\begin{tabular}{|c|c|c|c|c|c|}
\hline \multirow{2}{*}{ Water quality index } & \multicolumn{5}{|c|}{ Classification } \\
\hline & I & II & III & IV & $\mathrm{V}$ \\
\hline TP (ug/L) & $<1$ & $<4$ & $<23$ & $<110$ & $<660$ \\
\hline $\mathrm{COD}(\mathrm{mg} / \mathrm{L})$ & $<0.09$ & $<0.36$ & $<1.80$ & $<7.10$ & $<27.10$ \\
\hline $\mathrm{SD}(\mathrm{m})$ & $>37$ & $>12$ & $>2.4$ & $>0.55$ & $>0.17$ \\
\hline $\mathrm{TN}(\mathrm{mg} / \mathrm{L})$ & $<0.02$ & $<0.06$ & $<0.31$ & $<1.20$ & $<4.60$ \\
\hline
\end{tabular}

TABLE 7: Correlation coefficient between indicators.

\begin{tabular}{lcccc}
\hline Indicators & TP & COD & SD & TN \\
\hline TP & 1.0000 & 0.8821 & -0.4242 & 0.7907 \\
COD & 0.8821 & 1.0000 & -0.5350 & \\
SD & -0.4242 & -0.5350 & 1.0000 & -0.8443 \\
TN & 0.7907 & 0.8443 & -0.5256 & 1.0000 \\
\hline
\end{tabular}

TABLE 8: Basic parameters of the improved CRITIC method.

\begin{tabular}{lcccc}
\hline Indicators & Mean & Standard deviation & Coefficient of variation & Weights, $\mathbf{w}_{j}$ \\
\hline TP & 89.3687 & 144.9379 & 1.6218 & 0.2601 \\
COD & 5.5463 & 7.0648 & 1.2738 & 0.1671 \\
SD & 13.6542 & 19.2955 & 1.4132 & 0.3803 \\
TN & 0.8845 & 1.1418 & 1.2909 & 0.1925 \\
\hline
\end{tabular}

TABLE 9: Evaluation results and comparison.

\begin{tabular}{|c|c|c|c|c|c|c|c|c|c|c|}
\hline \multirow{2}{*}{ Samples } & \multicolumn{5}{|c|}{$\mu(x)$} & \multirow{2}{*}{ Proposed model } & \multirow{2}{*}{ G } & \multirow{2}{*}{$\mathrm{H}[54]$} & \multirow{2}{*}{ I } & \multirow{2}{*}{$\mathrm{J}$} \\
\hline & $\mathrm{I}$ & II & III & IV & $\mathrm{V}$ & & & & & \\
\hline 1 & 0.9017 & 0.2415 & 0.0000 & 0.0001 & 0.0000 & I & $\mathrm{I}$ & I & $\mathrm{I}$ & $\mathrm{I}$ \\
\hline 2 & 0.8306 & 0.0000 & 0.0000 & 0.0002 & 0.0000 & I & $\mathrm{I}$ & I & $\mathrm{I}$ & $\mathrm{I}$ \\
\hline 3 & 1.0000 & 0.0433 & 0.0004 & 0.0000 & 0.0000 & I & $\mathrm{I}$ & I & $\mathrm{I}$ & $\mathrm{I}$ \\
\hline 4 & 0.7153 & 0.4139 & 0.0003 & 0.0002 & 0.0000 & I & I & I & $\mathrm{I}$ & $\mathrm{I}$ \\
\hline 5 & 0.8398 & 0.1366 & 0.0028 & 0.0001 & 0.0000 & I & $\mathrm{I}$ & I & $\mathrm{I}$ & $\mathrm{I}$ \\
\hline 6 & 0.3444 & 0.6709 & 0.0030 & 0.0006 & 0.0000 & II & II & II & II & II \\
\hline 7 & 0.0779 & 0.7580 & 0.2004 & 0.0022 & 0.0000 & II & II & II & II & II \\
\hline 8 & 0.0970 & 0.8852 & 0.1087 & 0.0023 & 0.0000 & II & II & II & II & II \\
\hline 9 & 0.1138 & 0.7728 & 0.0701 & 0.0040 & 0.0000 & II & II & II & II & II \\
\hline 10 & 0.0983 & 0.8972 & 0.0927 & 0.0023 & 0.0000 & II & II & II & II & II \\
\hline 11 & 0.0000 & 0.0386 & 0.8848 & 0.1891 & 0.0037 & III & III & III & III & III \\
\hline 12 & 0.0000 & 0.0226 & 0.7070 & 0.2781 & 0.0022 & III & III & III & III & III \\
\hline 13 & 0.0000 & 0.0149 & 0.5793 & 0.4198 & 0.0080 & III & III & III & III & III \\
\hline 14 & 0.0000 & 0.0459 & 0.8576 & 0.1385 & 0.0033 & III & III & III & III & III \\
\hline 15 & 0.0001 & 0.0617 & 0.7209 & 0.1236 & 0.0002 & III & III & III & III & III \\
\hline 16 & 0.0000 & 0.0012 & 0.1397 & 0.7201 & 0.0527 & IV & IV & IV & IV & IV \\
\hline 17 & 0.0000 & 0.0004 & 0.1194 & 0.7268 & 0.0656 & IV & IV & IV & IV & IV \\
\hline 18 & 0.0000 & 0.0001 & 0.0407 & 0.7740 & 0.1902 & IV & IV & IV & IV & IV \\
\hline 19 & 0.0000 & 0.0000 & 0.0241 & 0.6930 & 0.2952 & IV & IV & IV & IV & IV \\
\hline 20 & 0.0000 & 0.0001 & 0.0476 & 0.8349 & 0.1756 & IV & IV & IV & IV & IV \\
\hline 21 & 0.0000 & 0.0000 & 0.0000 & 0.0667 & 0.9133 & $\mathrm{~V}$ & $\mathrm{~V}$ & $\mathrm{~V}$ & $\mathrm{~V}$ & $\mathrm{~V}$ \\
\hline 22 & 0.0000 & 0.0000 & 0.0001 & 0.0432 & 0.9980 & $\mathrm{~V}$ & $\mathrm{~V}$ & $\mathrm{~V}$ & $\mathrm{~V}$ & $\mathrm{~V}$ \\
\hline 23 & 0.0000 & 0.0000 & 0.0001 & 0.0999 & 0.8533 & $\mathrm{~V}$ & $\mathrm{~V}$ & $\mathrm{~V}$ & $\mathrm{~V}$ & $\mathrm{~V}$ \\
\hline 24 & 0.0000 & 0.0000 & 0.0001 & 0.0838 & 0.9997 & $\mathrm{~V}$ & $\mathrm{~V}$ & $\mathrm{~V}$ & $\mathrm{~V}$ & $\mathrm{~V}$ \\
\hline 25 & 0.0000 & 0.0000 & 0.0003 & 0.1058 & 0.9393 & V & $\mathrm{V}$ & V & $\mathrm{V}$ & V \\
\hline 26 & 0.0000 & 0.0000 & 0.0013 & 0.1856 & 0.8790 & $\mathrm{~V}$ & $\mathrm{~V}$ & $\mathrm{~V}$ & $\mathrm{~V}$ & $\mathrm{~V}$ \\
\hline 27 & 0.0000 & 0.0000 & 0.0032 & 0.2639 & 0.7374 & $\mathrm{~V}$ & $\mathrm{~V}$ & IV & $\mathrm{V}$ & $\mathrm{V}$ \\
\hline 28 & 0.0000 & 0.0288 & 0.7833 & 0.2447 & 0.0026 & III & III & III & III & III \\
\hline 29 & 0.0000 & 0.0001 & 0.0131 & 0.2023 & 0.2950 & $\mathrm{~V}$ & IV & IV & $\mathrm{V}$ & $\mathrm{V}$ \\
\hline 30 & 0.0000 & 0.0008 & 0.0497 & 0.3316 & 0.0926 & IV & IV & IV & IV & III \\
\hline
\end{tabular}

Note: G represents the multidimensional connection cloud model based on the traditional CRITIC method; $\mathrm{H}$ represents the empirical value; I represents the multidimensional connection cloud model; J represents the one-dimensional connection cloud model. 
belongs to grade IV while it is very close to the boundary value of grade V. So, it is more reasonable for sample 27 to be judged as grade V. For sample 29, values of indicator TP and COD belong to grade IV, and values of the indicator SD and $\mathrm{TN}$ are at grade $\mathrm{V}$. The value of COD is nearer to the boundary value of grade $\mathrm{V}$. Therefore, it is more reasonable that the evaluation result of sample 29 is grade V, which is from the proposed model.

However, G (multidimensional connection cloud model based on traditional CRITIC method) judged sample 29 as grade IV, which was inaccurate. The improved CRITIC was used in the model presented in this article for deciding the weight. In contrast, the traditional CRITIC was used in G. The proposed model and G covered a multidimensional connection cloud model. It was found that the evaluation result of the model presented in this article was superior than that from G. The above words can prove that the improved CRITIC is better than the traditional CRITIC for weighting.

For sample 30, the values of TP and TN are at grade III, and values of indicators COD and SD are in grade V. They are both closer to the boundary value of grade IV. So, IV is a reasonable grade for sample 30 . Under the further statistical analysis of Table 9 , the multidimensional connection cloud model is the most credible. The similarity rate is based on the multidimensional connection cloud model here. According to formula (17), the similarity rate of the proposed model reaches $100 \%$, which is higher than $96.7 \%$ of the multidimensional connection cloud model based on the traditional CRITIC method, $93.3 \%$ of experience value, and $96.7 \%$ of the one-dimensional connection cloud model. These results demonstrate that it is effective for the proposed method to be used to assess water eutrophication.

\section{Conclusions}

The evaluation of water eutrophication is of enormous significance. However, it is usually affected by various random and fuzzy elements. A multidimensional connection cloud model combined with an improved CRITIC method was proposed to consider uncertainty in the water eutrophication evaluation. And a final analysis for comparison was undertaken to acknowledge the accuracy of the proposed model. Some meaningful conclusions are as follows:

(1) The improved CRITIC method was adopted to assign the weight of various indicators. Compared with the traditional CRITIC method, it contains comprehensive content of the information in indicators and reflects the correlation between multiple indicators. "The variation coefficient" is contained in the improved CRITIC method. Its calculation formula includes the absolute value of the correlation coefficient between the indicators. The weight based on the enhanced CRITIC method is more reasonable than the weight based on the traditional CRITIC method.

(2) Due to possible differences in different intervals, the application of the traditional one-dimensional cloud model is limited to a certain extent. And the one- dimensional cloud model is not good at handling multiple indicators and samples. In the face of various indexes and numerous samples, the multidimensional connection cloud model is beneficial for avoiding the excessive influence of a single index and overcoming the subjective shortcoming of the traditional cloud model while determining numerical feature parameters. The calculation of the proposed model is also more accessible than the one-dimensional cloud model.

(3) Case study demonstrates that it is effective and realistic for the proposed model to evaluate the degree of water eutrophication. The improved CRITIC method and the multidimensional connection cloud model are excellent mathematical theories. The prospect of applying them to analyze uncertainty is ideal. On the one hand, the proposed model can objectively synthesize the internal information contained in each indicator. On the other hand, the model is a valid method for estimating the effect of each indicator on the evaluation process.

(4) The method proposed here can quantitatively characterize the randomness and ambiguity brought by evaluation indexes. And it can reflect the mutual relationship between various indicators, the combined effect of all indicators, and the conversion trend of evaluation grades. So, it provides a new reference basis for eutrophication evaluation. At the same time, the causes of eutrophication are complex. To optimize the coupling mode among different indicators in practical applications, the proposed model still needs further study in the future.

\section{Data Availability}

The data appearing in this study can be obtained from the corresponding author.

\section{Conflicts of Interest}

The authors claim that there are no conflicts of interest with respect to the publication of this article.

\section{Authors' Contributions}

M. W. and J. Y. conceptualized the study and prepared the original draft and were responsible for methodology; J. Y. and D. W. were responsible for software; M. W. and G. C. validated the data; M. W. performed formal analysis; G. C. and $D$. W. investigated the data and contributed to data curation; M. W. and D. W. were responsible for software; M. W., J. Y., F. S., and J. J. reviewed and edited the manuscript; G. C. and D. W. visualized the study; M. W. performed study supervision; D. W. was involved in funding acquisition.

\section{Acknowledgments}

The National Natural Science Foundation of China (grant no. 41172274), the National Key Research and Development 
Program (grant no. 2017YFC1502405), and Anhui \& Huaihe River Institute of Hydraulic Research are acknowledged.

\section{References}

[1] X. M. Song, Screening of Phosphorus Accumulating Microorganisms and Research on Their Removal Effect on Phosphorus in Eutrophic Water, Master Thesis, Nanjing University of Science and Technology, Nanjing, China, 2015.

[2] X. Chen, Y. H. Wang, T. Sun et al., "Effects of sediment dredging on nutrient release and eutrophication in the gatecontrolled estuary of northern Taihu Lake," Journal of Chemistry, vol. 2021, Article ID 7451832, 2021.

[3] J. Chen, H. Zhang, L. Liu et al., "Effects of elevated sulfate in eutrophic waters on the internal phosphate release under oxic conditions across the sediment-water interface," The Science of the Total Environment, vol. 790, Article ID 148010, 2021.

[4] H. Yu, "The hazards of water eutrophication and the countermeasures," Intelligent City, vol. 5, no. 17, pp. 147-148, 2019.

[5] Y. M. Wang and S. L. Zhou, "Characteristics of water eutrophication and its countermeasures in Zhejiang province," Environmental Monitoring in China, vol. 34, no. 6, pp. 170178, 2018.

[6] S. L. Zhou, Nitrogen Removal Characteristics of IndigenousOligotrophic Aerobic Denitrifiers via in Situ Oxygen Enhancement and Technology Application Research, PhD Thesis, Xi'an University of Architecture and Technology, Xi'an, China, 2017.

[7] W. P. Cao, L. Sun, Y. M. Wang, Q. Q. Heng, and X. H. Qi, "Application status and development trend of carrier in denitrification of eutrophic water," Journal of Xuzhou Institute of Technology (Natural Sciences Edition), vol. 34, no. 4, pp. 83-87, 2019.

[8] W. L. Liang, Study on Water Quality Evaluation Methods and Design of Lake Eutrophication Evaluation System, Master Thesis, University of Electronic Science and Technology of China, Chengdu, China, 2017.

[9] J. A. Ma and H. Q. Li, "Preliminary discussion on eutrophication status of lakes, reservoirs and rivers in China and overseas," Resources and Environment in the Yangtze Basin, vol. 11, no. 6, pp. 575-578, 2002.

[10] G. M. Capriulo, G. Smith, R. Troy, G. H. Wikfors, J. Pellet, and C. Yarish, "The planktonic food web structure of a temperate zone estuary, and its alteration due to eutrophication," $\mathrm{Nu}$ trients and Eutrophication in Estuaries and Coastal Waters, vol. 475, no. 1, pp. 263-333, 2002.

[11] Q. Liu, M. Wang, T. Zhou, F. Shen, and J. Jin, "A connection cloud model coupled with extenics for water eutrophication evaluation," Earth Science India, vol. 12, no. 4, pp. 659-669, 2019.

[12] C. H. Feng, Research on Eutrophication Assessment Predication of Lakes and Reservoirs, Master Thesis, Xi'an University of Technology, Xi'an, China, 2004.

[13] J. H. Wu, C. Y. Xue, R. Tian, and S. T. Wang, "Lake water quality assessment: a case study of Shahu Lake in the semiarid loess area of northwest China," Environmental Earth Sciences, vol. 76, no. 5, pp. 1-15, 2017.

[14] J. B. Tu, Q. F. Zhang, F. X. Niu et al., "Spatio-temporal variational analysis and prediction of water quality in the BeiTang Estuary and its coastal sea areas," Marine Sciences, vol. 36, no. 8, pp. 98-103, 2012.

[15] W. Zhang, J. Shen, and J. Wang, "Linking pollution to biodiversity and ecosystem multifunctionality across benthicpelagic habitats of a large eutrophic lake: a whole-ecosystem perspective," Environmental Pollution, vol. 285, Article ID 117501, 2021.

[16] W. B. Pang, Q. F. Zhang, Y. Z. Chen, J. B. Tu, and Y. Y. Ma, "Eutrophication evaluation of Tianjin coastal waters in Bohai Bay based on PSR model and analytic hierarchy process," Transactions of Oceanology and Limnology, vol. 6, pp. 111-118, 2020.

[17] D. Quan, X. H. Shi, S. N. Zhao, S. Zhang, and J. J. Liu, "Eutrophication of lake Ulansuhai in 2006-2017 and its main impact factors," Hupo Kexue/Journal of Lake Sciences, vol. 31, no. 5, pp. 1259-1267, 2019.

[18] G. Z. Zhi, Y. N. Chen, X. Z. Yuan, and G.-M. Zeng, “Assessment model for Dongting Lake's comprehensive nutrition state based on extended blind number," Zhongguo Huanjing Kexue/China Environmental Science, vol. 33, no. 11, pp. 2095-2101, 2013.

[19] W. Zou, G. W. Zhu, Y. J. Cai, and H. Xu, "The limitations of comprehensive trophic level index (TLI) in the eutrophication assessment of lakes along the middle and lower reaches of the Yangtze River during summer season and recommendation for its improvement," Hupo Kexue/Journal of Lake Sciences, vol. 32, no. 1, pp. 36-47, 2020.

[20] T. Y. Lin, X. Z. Yuan, Q. H. Tang et al., "Application of set pair analysis model based on entropy weight in evaluation of lake eutrophication," Environmental Engineering, vol. 32, no. 11, pp. 141-145+76, 2014.

[21] N. T. Giao, H. T. H. Nhien, P. K. Anh, and D. V. Ni, "Classification of water quality in low-lying area in Vietnamese Mekong delta using set pair analysis method and Vietnamese water quality index," Environmental Monitoring and Assessment, vol. 193, no. 6, p. 319, 2021.

[22] M. W. Wang, J. L. Jin, and Y. L. Zhou, Set Pair Analysis Based Coupling Methods and Applications, Science Press, Beijing, China, 2014.

[23] D. Wang, D. Zeng, V. P. Singh et al., "A multidimension cloud model-based approach for water quality assessment," Environmental Research, vol. 149, pp. 113-121, 2016.

[24] D. Li, C. Liu, and W. Gan, "A new cognitive model: cloud model," International Journal of Intelligent Systems, vol. 24, no. 3, pp. 358-375, 2009.

[25] X. Y. Xu, M. W. Wang, Y. F. Li, and L. B. Zhang, "Risk evaluation of debris flow hazard based on asymmetric connection cloud model," Mathematical Problems in Engineering, vol. 2017, Article ID 5348149, 8 pages, 2017.

[26] M. Wang, X. Wang, Q. Liu, F. Shen, and J. Jin, "A novel multidimensional cloud model coupled with connection numbers theory for evaluation of slope stability," Applied Mathematical Modelling, vol. 77, pp. 426-438, 2020.

[27] M. W. Wang and J. L. Jin, The Theory and Applications of Connection Numbers, Beijing Science Press, Beijing, China, 2017.

[28] J. Yao, G. Wang, B. Xue et al., "Assessment of lake eutrophication using a novel multidimensional similarity cloud model," Journal of Environmental Management, vol. 248, Article ID 109259, 2019.

[29] M. Wang, Y. Wang, F. Shen, and J. Jin, “A novel classification approach based on integrated connection cloud model and game theory," Communications in Nonlinear Science and Numerical Simulation, vol. 93, Article ID 105540, 2021.

[30] A. R. Krishnan, M. M. Kasim, R. Hamid, and M. F. Ghazali, “A modified CRITIC method to estimate the objective weights of decision criteria," Symmetry, vol. 13, p. 973, 2021. 
[31] L. Chen, Y. Guo, and L. Li, "Structural dynamic model updating based on multi-level weight coefficients," Applied Mathematical Modelling, vol. 71, pp. 700-711, 2019.

[32] Z. Ma, C. Shao, S. Ma, and Z. Ye, "Constructing road safety performance indicators using fuzzy delphi method and grey delphi method," Expert Systems with Applications, vol. 38, no. 3, pp. 1509-1514, 2011.

[33] R. Li, Y. Li, H. Xu, and H. Liu, "Assessment on typical power supply mode for important power consumers based on analytical hierarchy process and expert experience," Power System Technology, vol. 38, pp. 2336-2341, 2014.

[34] H. Deng, C.-H. Yeh, and R. J. Willis, "Inter-company comparison using modified topsis with objective weights," Computers \& Operations Research, vol. 27, no. 10, pp. 963973, 2000.

[35] G. Obulaporam, N. Somu, G. R. Manilyer Ramani, A. K. Boopathy, and S. S. Vathula Sankaran, "GCRITICPA: a CRITIC and grey relational analysis based service ranking approach for cloud service selection," in Proceedings of the Third International Conference on Intelligent Information Technologies, ICIIT, Chennai, India, December 2018.

[36] G. O. Odu, "Weighting methods for multi-criteria decision making technique," Journal of Applied Sciences and Environmental Management, vol. 23, no. 8, pp. 1449-1457, 2019.

[37] J. Ma, Z.-P. Fan, and L.-H. Huang, "A subjective and objective integrated approach to determine attribute weights," European Journal of Operational Research, vol. 112, no. 2, pp. 397-404, 1999.

[38] N. Mahmoody Vanolya and M. Jelokhani-Niaraki, "The use of subjective-objective weights in GIS-based multi-criteria decision analysis for flood hazard assessment: a case study in Mazandaran, Iran," Geojournal, vol. 86, no. 1, pp. 379-398, 2021.

[39] Y. Shao, X. Han, H. Wu, and C. G. Claudel, "Evaluating signalization and channelization selections at intersections based on an entropy method," Entropy, vol. 21, no. 8, pp. 808-831, 2019.

[40] Y. Shao, Z. Luo, H. Wu et al., "Evaluation of two improved schemes at non-aligned intersections affected by a work zone with an entropy method," Sustainability, vol. 12, no. 14, pp. 5494-5517, 2020.

[41] E. K. Zavadskas and V. Podvezko, "Integrated determination of objective criteria weights in MCDM," International Journal of Information Technology \& Decision Making, vol. 15, no. 02, pp. 267-283, 2016.

[42] P. Rani, A. R. Mishra, R. Krishankumar, K. S. Ravichandran, and S. Kar, "Multi-criteria food waste treatment method selection using single-valued neutrosophic-CRITIC-MULTIMOORA framework," Applied Soft Computing, vol. 111, Article ID 107657, 2021.

[43] B. Pan, S. Liu, Z. Xie, Y. Shao, X. Li, and R. Ge, "Evaluating operational features of three unconventional intersections under heavy traffic based on critic method," Sustainability, vol. 13, no. 8, pp. 4098-4127, 2021.

[44] J. C. Wang, M. J. Huang, and J. Guo, "Rock burst evaluation using the CRITIC algorithm-based cloud model," Frontiers in Physics, vol. 8, Article ID 593701, 2021.

[45] D. Diakoulaki, G. Mavrotas, and L. Papayannakis, "Determining objective weights in multiple criteria problems: the critic method," Computers \& Operations Research, vol. 22, no. 7, pp. 763-770, 1995.

[46] D. Y. Li, H. J. Meng, and X. M. Shi, "Membership clouds and membership cloud generators," Journal of Computer Research and Development, vol. 32, pp. 16-21, 1995.
[47] J. Y. Long, X. Wang, and J. L. Jin, "Multi-dimensional connection cloud model of rock mass quality evaluation of caverns," Chinese Journal of Underground Space and Engineering, vol. 16, pp. 1420-1425, 2020.

[48] D. Y. Li and Y. Du, Artificial Intelligence with Uncertainty, Beijing National Defence Industry Press, Beijing, China, 2014.

[49] M. W. Wang, X. Wang, J. Y. Long, and J. L. Jin, "Risk assessment of debris flow based on multidimensional connection normal cloud model," Yingyong Jichu yu Gongcheng Kexue Xuebao/Journal of Basic Science and Engineering, vol. 29, no. 2, pp. 368-375, 2021.

[50] E. Jekatierynczuk-Rudczyk, P. Zieliński, M. Grabowska, J. Ejsmont-Karabin, M. Karpowicz, and A. Więcko, "The trophic status of Suwałki Landscape Park lakes based on selected parameters (NE Poland)," Environmental Monitoring and Assessment, vol. 186, no. 8, pp. 5101-5121, 2014.

[51] B. Y. Yang, Simulation Study on Eutrophication of Chaohu Lake Based on Statistical Method, Master Thesis, Anhui University of Science \& Technology, Huainan, China, 2020.

[52] L. L. Chen and L. H. Jin, "An improved fuzzy comprehensive evaluation method of eutrophication for lakes and reservoirs," Zhongguo Huanjing Kexue/China Environmental Science, vol. 34, no. 12, pp. 3223-3229, 2014.

[53] J. Li, M. W. Wang, J. Y. Long, and J. L. Jin, "A comprehensive connection cloud model based on game theory for the evaluation of water eutrophication," Environmental Engineering, vol. 39, no. 6, pp. 192-197, 2021.

[54] J. L. Jin, Y. M. Wei, and J. Ding, "Projection pursuit model for comprehensive evaluation of water quality," Acta Scientiae Circumstantiae, vol. 4, pp. 431-434, 2001. 